\title{
Predictors of Recurrence after a First Unprovoked Seizure in Childhood: A Prospective Study
}

\author{
N. Akter, M. M. Rahman, S. Akhter, K. Fatema, and S. M. B. Billah
}

\section{ABSTRACT}

\begin{abstract}
The second part of the revised definition of epilepsy by ILAE in 2014 allows a condition to be considered epilepsy after one seizure if there is a high risk of having another seizure; if the risk factor is not precisely be known we have to wait for another seizure. This definition necessitates search for probable risk factors. We aimed this study to assess the recurrence rate and associated risk factors for recurrences after a first unprovoked seizure in children within two years of first attack. This prospective study was conducted on in Banglabandhu Sheikh Mujib Medical University (BSMMU) from June 2016 to December 2018. Among 137 children finally 120 children aged between1 month to 14 years after a first seizure were followed up for 2 years. Diagnosis of seizure was confirmed on the basis of diagnostic criteria and none of the children was treated by any antiepileptic drugs after first episode. Overall recurrence rate within 2 years of follow up was $38 \%$. Majority of recurrence $(65 \%)$ observed within 6-10 months of initial seizure. Significant risk factors were an abnormal EEG finding $(\mathrm{p}=<0.001)$, focal seizure $(\mathrm{p}=<0.001)$, seizure at sleep $(p=0.001)$ and initial presentation with status epilepticus $(p=0.001)$. Abnormal neuroimage findings were also associated with seizure recurrence, but it was not statistically significant. Age of the patients and underlying motor and cognitive delay was not a significant risk factor for recurrence. A great percentage of first seizure didn't show recurrence but there are so many factors can determine the possibilities of recurrence, early identification of risk factors specially the focal pattern of seizure, seizure in sleep, status epilepticus and abnormal electrophysiology are the best predictive factors of recurrence, so identifying the high risk group of recurrence helps to initiate early antiepileptic drug and prevent further recurrence.
\end{abstract}

Keywords: First unprovoked seizure, seizure recurrence, childhood seizure.
Published Online: June 26,2021

ISSN: $2736-5476$

DOI: $10.24018 /$ ejclinicmed.2021.2.3.42

\section{N. Akter*}

Dhaka Medical College, Bangladesh.

(e-mail: nazninruby73@gmail.com)

M. M. Rahman

Bangabandhu Sheikh Mujib Medical University, Dhaka, Bangladesh.

(e-mail:

mizanur_rahman_1955@yahoo.com)

S. Akhter

Bangabandhu Sheikh Mujib Medical

University, Dhaka

(e-mail: shaheen@ cnacbangladesh.org)

K. Fatema

Bangabandhu Sheikh Mujib Medical

University, Dhaka, Bangladesh.

(e-mail: mailmonami@gmail.com)

S. M. B. Billah

Sher-e Bangla Medical College,

Barishal, Bangladesh.

*Corresponding Author

\section{INTRODUCTION}

Epileptic seizure is a common childhood neurological disorder results from a variety of causes with reported recurrence risk after first seizure range from $23 \%$ to $71 \%$ from different studies [1]-[5]. The first unprovoked seizure is always devastating and frightening events for the parents so it is very crucial to make a rational decision whether treatment should be started or not after a first unprovoked seizure. Age of onset of first seizure, gender, positive family history, perinatal history, seizure type, EEG result all these factors have shown an association with recurrences from various studies, but they still remain inconclusive [6], [7]. Majorities of study have been shown epileptiform discharge in electroencephalogram (EEG) and remote symptomatic seizure as main factors for recurrences [8], [9]. According to the revised definition of ILAE, 2014[10], Item 1 of the definition is same as the old definition of epilepsy; Item 2 allows a condition to be considered epilepsy after one seizure if there is a high risk of having another seizure. If the risk factors are not precisely be known, we have to wait for another seizure. This definition allows researching the probable risk factors. So, knowledge of recurrence after first unprovoked seizure is essential to consider a condition which allows treating the child with antiepileptics. As there is no prospective studies in Bangladesh to observe the recurrence rate after first unprovoked seizure and the risk factors affecting the recurrences the present study aimed to find out rate of recurrences after the first episode of unprovoked seizure and the associated risk factors for recurrence.

\section{METHODOLOGY}

This prospective study was carried out in the Institute of pediatric Neurodisorder and Autism (IPNA), Bangabandhu Sheikh Mujib Medical University (BSMMU), Dhaka. All patients who came with first unprovoked seizure during period of June 2016 to December 2016 were followed up for further two years. Children aged 1 month to 14 years with history of one unprovoked seizure were included as cases and 
those who developed recurrence during follow up period were included for comparison. Children with epilepsy syndrome like infantile spasm, absence seizure, myoclonic seizure were excluded from the study as it has $100 \%$ recurrence risk. Suspected neurometabolic and neurodegenerative disorder and those who were unwilling to give informed consent and unwilling to be available for follow-up also excluded from the study. The study enrolled 137 patients. But only 120 has completed 2 years' follow-up so the final analysis was done with 120 patients.

\section{DAta Collection Procedure}

After taking complete history, general physical and neurodevelopmental assessment was done for all enrolled patients. Patient who matched the inclusion and exclusion criteria according to history, physical examination and freely gave their informed consent was selected for the study. All children underwent electroencephalography and neuroimaging.

Psychological assessment was done by using BSID-II for 1 month-3 years old children, IBAS/ WIPPSI for 3-6years old children and WISC-IV for 6-15 years old children. Cognitive level was designated as normal or impaired with cut off IQ of 70 .

Patients were instructed for follow up regularly up to 2 years from the first seizure by hospital visits and by telephonic interviews. No antiepileptic drug was prescribed after the first seizure.

All information was collected in a preformed semi structured questionnaire. Age of patients and age of onset of seizures were converted into months. Data were processed and analyzed using computer software SPSS (Statistical Package for Social Science) version 21. The data presented on categorical scale are expressed as frequency and corresponding percentage, while the quantitative data are presented as mean and standard deviation $( \pm \mathrm{SD})$. Qualitative variables were assessed with chi-square test and the quantitative variables were analyzed with Student's t-test or one-way ANOVA as applicable. A $p$ value of $\leq 0.05$ was considered significant.

\section{RESULTS}

The overall rate of recurrences after first seizure is $41.6 \%$ $(n=50)$. Maximum recurrences occur within 18 months of initial attack and as early as 10 days of initial attack. Average time of recurrences was $3.6 \pm 3.9$ months. The rest 70 children had no recurrence. Table 1 shows that early age of patients and early age of onset of seizure are significantly associated with recurrence of seizure $(\mathrm{p}=0.04)$ while higher duration of seizure is also nearly significantly $(\mathrm{p}=0.06)$ associated with the outcome.

Our analysis between types of seizures and recurrence (Fig. 1) shows that focal and focal with bilateral seizures are significantly associated with recurrence compared to generalized seizure.
TABLE I: DEMOGRAPHIC AND CLINICAL CHARACTERISTICS OF THE STUDY POPULATION

\begin{tabular}{cccc}
\hline $\begin{array}{c}\text { Patient } \\
\text { Characteristics }\end{array}$ & No recurrence & Recurrence & $\begin{array}{c}\mathrm{P} \\
\text { value }\end{array}$ \\
\hline Age (months) & $74.69 \pm 48.72$ & $55.76 \pm 48.58$ & 0.04 \\
$\begin{array}{c}\text { Monthly income } \\
\text { Age of onset of } \\
\text { seizure(month) } \\
\text { Duration of } \\
\text { seizure(min) }\end{array}$ & $15264.71 \pm 6609.85$ & $16160.00 \pm 8538.89$ & 0.55 \\
\hline
\end{tabular}

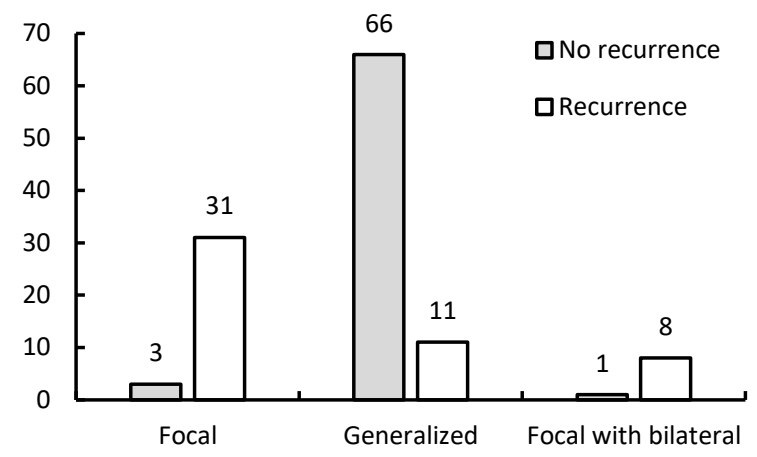

Fig. 1. Distribution of patients according to types of seizure.

While we look at the EEG picture (Table II), we find that an initial abnormal EEG finding is strongly associated with recurrence $(\mathrm{p}<0.001)$ compared to a normal initial EEG.

TABLE II: DiSTRIBUTION OF PATIENTS ACCORDING TO INITIAL EEG

\begin{tabular}{cccc}
\multicolumn{4}{c}{ FINDINGS } \\
\hline \multirow{2}{*}{ EEG findings } & $\begin{array}{c}\text { No recurrence } \\
\mathrm{n}(\%)\end{array}$ & $\begin{array}{c}\text { Recurrence } \\
\mathrm{n}(\%)\end{array}$ & \multirow{2}{*}{ P value } \\
\hline Normal & $70(100)$ & $12(24)$ & $<0.001$ \\
Abnormal & $0(0)$ & $38(76)$ & \\
\hline
\end{tabular}

Fig. 2 shows a detailed association of different types of seizures with recurrence. And it shows that the initial abnormal EEG finding is associated with recurrence.

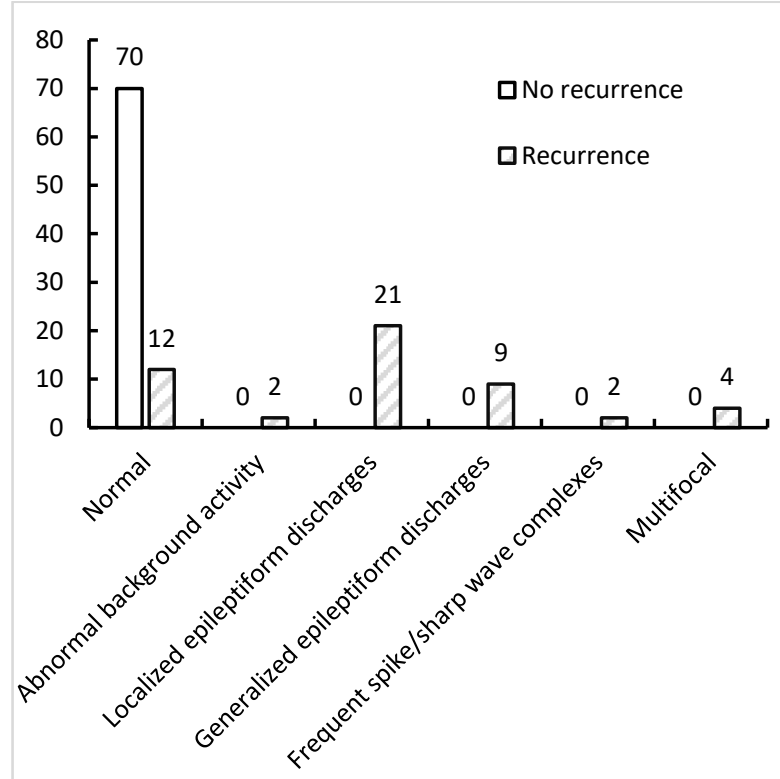

Fig.2. Distribution of patients according to EEG picture.

Table III depicts that structural abnormalities and other remote symptomatic etiologies are significantly associated with recurrence of seizure. Similarly, co-morbidities like cerebral palsy, motor or cognitive delay are also significantly 
associated with risk of seizure as evidenced in Table IV.

TABLE III: ETIOLOGY OF SEIZURE IN BOTH GROUPS OF PATIENTS

\begin{tabular}{cccc}
\hline Etiology of seizure & $\begin{array}{c}\text { No recurrence } \\
\mathrm{n}(\%)\end{array}$ & $\begin{array}{c}\text { Recurrence } \\
\mathrm{n}(\%)\end{array}$ & \multirow{2}{*}{ P value } \\
\hline Unknown & $64(91)$ & $26(52)$ & \\
Structural & $06(8.5)$ & $19(38)$ & \\
Post traumatic & $00(0)$ & $01(2)$ & $<0.001$ \\
Post meningitic & $00(0)$ & $02(4)$ & \\
lencephalitic & $00(0)$ & $02(4)$ & \\
Post stroke & & & \\
\hline
\end{tabular}

TABLE IV: CO-MORBIDITIES RELATED TO BOTH GROUPS OF PATIENTS

\begin{tabular}{cccc}
\hline Co morbidities & $\begin{array}{c}\text { No recurrence } \\
\mathrm{n}(\%)\end{array}$ & $\begin{array}{c}\text { Recurrence } \\
\mathrm{n}(\%)\end{array}$ & P value \\
\hline No & $63(90)$ & $20(40)$ & \\
Speech \& language & $01(1.4)$ & $05(10)$ & \\
delay & $01(1.4)$ & $07(14)$ & $<0.001$ \\
Motor delay & $03(4.2)$ & $11(22)$ & \\
Cerebral Palsy & $01(1.4)$ & $01(2)$ & \\
Learning & $01(1.4)$ & $06(12)$ & \\
Disabilities & & & \\
Cognitive delay & &
\end{tabular}

TABLE M5: FREQUENCY DISTRIBUTION OF RISK FACTORS FOR RECURRENCE

\begin{tabular}{cccc}
\hline Risk factors & $\begin{array}{c}\text { No recurrence } \mathrm{n} \\
(\%)\end{array}$ & $\begin{array}{c}\text { Recurrence } \\
\mathrm{n}(\%)\end{array}$ & P value \\
\hline Age of onset & $74.69 \pm 48.72$ & $55.76 \pm 48.58$ & 0.04 \\
Focal seizure & $03(4.2)$ & $31(62)$ & $<0.001$ \\
Status & $00(0)$ & $07(14)$ & $<0.001$ \\
Epilepticus & $01(1.4)$ & $05(10)$ & 0.63 \\
F/H of Epilepsy & $02(2.8)$ & $14(28)$ & $<0.001$ \\
Neonatal seizure & $00(0)$ & $32(64)$ & $<0.001$ \\
Seizure in sleep & $10(14.2)$ & $24(48)$ & $<0.05$ \\
$\quad$ Delayed & $10(14.2)$ & $08(16)$ & 0.79 \\
development & $00(0)$ & $38(76)$ & $<0.001$ \\
H/O Febrile & Seizure & $13(26)$ & 0.06 \\
Abnormal EEG & $05(7.1)$ & & \\
Abnormal & &
\end{tabular}

\section{DISCUSSION}

We assessed an overall rate of recurrences to be $41.6 \%$. Different randomized controlled study reported different risks of recurrence. First Seizure Trial Group, 1993(FIR.S.T) study reported recurrence risk of $18 \%, 28 \%, 41 \%$ and $51 \%$ at 3,6,12 and 24 months, European-wide Multicenter Epilepsy and Single seizure study (MESS) has the same observations, taking from the summery of most of the studies an estimate 2 year recurrence risk in the range of $40 \%$, which matched the findings of our study [11]-[14]. Gender or geographical variability aren't associated with recurrence of seizure but early age of onset of first unprovoked seizure is significantly associated with recurrence. Though this finding is similar to Berg et al and Hirtz et al [4] [13] study, but other studies had no association of age of the first seizure with recurrence [15][17]. Of the seizures, focal seizures appear to be associated with higher risk of recurrence supported by studies where focal seizures have underlying symptomatic etiology [5], [14], [18]-[21]. We observe $62 \%$ focal seizure in recurrence group compared to only $4.2 \%$ in the non-recurrence group $(p<0.001)$. Other types of seizures like typical absence, myoclonic seizures, infantile spasm are more likely present as cluster of seizures or status, and they usually do not present as first seizure. These types of seizures should have to be treated as early as possible with specific drugs. Some studies related to adult epilepsy found multiple seizures in a day or first seizure as status epilepticus to be associated with high risk of recurrence [5], [22], while study on childhood epilepsy also found status epilepticus as a higher risk of recurrence [23]. Our study conforms with the finding that status epilepticus has a relation with further recurrence $(\mathrm{p}<0.001)$.

We did not find personal history of febrile seizure or positive family history of epilepsy to be associated with recurrence, though some studies have found the positive association [14], [18], [20]. One study considered consanguinity and family history as a possible risk factor, but here we did not find, and this result suggests that epilepsy is a disorder of multifactorial etiology rather than recessive disorder [24]. Prognostic significance of prior febrile seizure in a child with first unprovoked seizure shows equivocal results. Some studies have shown high recurrence association with remote symptomatic first unprovoked seizure compared to cryptogenic first seizure [12], [20], [25]. Febrile seizure is not a risk factors of recurrence in our study.

Here in this study history of neonatal seizure secondary to HIE (II), neonatal sepsis, metabolic derangement or dyselectrolytemic condition were significantly associated with recurrence. Around $28 \%$ of children with the group of recurrence had history of neonatal seizure though most of the related study did not support these findings. Occurrence of first seizure during sleep is associated with an increased risk of recurrence which is supported by most of the related studies [1], [13], [26]-[30]. In this study among the recurrence group $64 \%$ have experienced seizure in sleep and has no history of seizure in sleep any of the patient in the nonrecurrence group, with a highly significant association $(\mathrm{p}<0.001)$. Delayed psychomotor development is another significant risk factor for recurrence in this study which has been supported by the study done by Satroink $\mathrm{H}$ and Pairoj $\mathrm{B} 1,8$. An EEG with epileptiform discharge proved as a great risk factors for recurrence by different prospective studies [1], [3], [4], [12]-[14], [31], [32]. Patients with abnormal EEG $(76 \%)$ were associated with recurrence in our study. Abnormal neuroimage findings also came up as possible risk factor for recurrence by some study [1], [13]. In our study, $26 \%$ patients have abnormal neuroimage findings among the recurrence group compared to only $7.1 \%$ among the nonrecurrence group.

It is necessary to search the possible risk factors of recurrence before deciding to initiate any treatment after first unprovoked seizure. There should be a good proportion of children with single seizure who would never have a further seizure. So, it is important to predict the risk factors of recurrence to restrict unnecessary and over treatment with antiepileptics. Without having any risk factors, researchers advised to wait until second seizure, to start long term anticonvulsants treatment [33]

Our study has some limitations. We collate all the suspected risk factors in a common table (Table V) without constructing any linear model. But the findings will aid the future researchers to construct appropriate model for the risk factors and predict the risk. 


\section{CONCLUSION}

Our study determined early identification of risk factors specially the focal pattern of seizure, seizure in sleep, status epilepticus and abnormal electrophysiology to be the important predictive factors for the possibilities of recurrence.

\section{REFERENCES}

[1] Stroink H, Brouwer OF, Arts WF, Greerts AT, Peters ACB, Donselaar CAV. The first unprovoked, untreated seizure in childhood: a hospital based study of the accuracy of the diagnosis, rate of recurrence, and long term outcome after recurrence, Dutch study of epilepsy in childhood. J NeurolNeurosurg Psychiatry. 1998;64:595-600.

[2] Pearce JL, Mackintosh HT. Prospective study of convulsions in childhood. N Z Med J. 1979;89:1-3

[3] Camfield PR, Camfield CS, Dooley JM, Tibbles JAR, Fung T, Garner B. Epilepsy after a first unprovoked seizure in childhood. Neurology. 1985;35:1657-60.

[4] Hirtz DG, Ellenberg JH, Nelson KB. The risk of recurrence of nonfebrile seizures in children. Neurology 1984;34:637-40.

[5] Hauser WA, Rich SS, Annergers JF, Anderson VE. Seizure recurrence after a first unprovoked seizure: An extended follow up. Neurology. 1990; 40: 1163-70.

[6] Winckler MI, Rotta NT. Prognostic factors for recurrence of a first seizure during childhood. ArqNeuropsiquiatr. 1997;55:749-56.

[7] Scotoni AE, Guerriero MM, De Abreu HJ. First epileptic crisis. Analysis of risk of recurrence. ArqNeuropsiquiatr. 1999;57:392-400

[8] Pairoj B. Risk of recurrence following a first unprovoked seizure in Thai children. Neurol J Southeast Asia. 2003;8:25-29.

[9] Shinner S, Berg AT, Moshe SL, Petix M, Maytal J, Kang H et al. Risk of seizure recurrence following a first unprovoked seizure in childhood: a prospective study. Pediatrics. 1990; 85: 1076-85.

[10] Fisher RS, Acevedo C, Arzimanoglou A, Bogacz A, Cross H, Elger CE et al. A practical clinical definition of epilepsy. Epilepsia, 2014;55(4):475-82.

[11] Marson A, Jacoby A, Johnson A, Gamble C, Chadwick D. Immediate versus differed antiepileptic drug treatment for early epilepsy and single seizures: a randomized controlled trial. Lancet, 2005; 365: 2007 13.

[12] Berg AT, Shinner S, Testa FM, Levy SR, Frobish D, Smith S, Beckerman B. Status epilepticus after the initial diagnosis of epilepsy in children. Neurology, 2004:63:1027-34.

[13] Berg AT, Shinner S. The risk of seizure recurrence following a first unprovoked seizure: a quantatative review. Neurology,1991;41:965972.

[14] First Seizure Trial Group. Randomized clinical trial of the efficacy of the antiepileptic drugs in reducing the risk of relapse after a first unprovoked tonic-clonic seizure. Neurology,1993; 43: 478-83.

[15] Winckler MI, Rotta NT. Clinical and electrographic follow up after a first unprovoked seizure. Pediatr Neurol.2004;30:201-6.

[16] Maia C, Moreira AR, Lopes T, Martins C.Risk of recurrence after a first unprovoked seizure in children. J Pediatr (Rio J). 2016. http://dx.doi.org/10.1016/j.jped.2016.07.001.

[17] Kim LG, Johnson TL, Marson AG, Chadwick DW. Prediction of risk of seizure recurrence after a single seizure and early epilepsy: further result from the MESS trial. Lancet Neurol, 2006: 1780-85.
[18] Ramos LJ, Cassinello GE, Carrasco Marina LL, Vazquez LM, Martin Gonzalez MM, Munoz HA. Seizure recurrence after a first unprovoked seizure in childhood: a prospective study. Epilepsia,2000;41:1005-13.

[19] Bora I, Seckin B, Zarifoglu M, Turan F, Sadikoglu SEO. Risk of recurrence after first unprovoked tonic clonic seizure in adults. J Neurol,1995;242:157-63.

[20] Berkovic SF, Scheffer IE. Febrile seizures: genetics and relationship to other epilepsy. CurrOpinNeurol, 1998;11:129-34.

[21] Mizorogi S, Kanemura H, Sano F, Sugita K, Aihara M. Risk factors for seizure recurrence in children after first unprovoked seizure. Pediatr Int. 2015;57:665-9.

[22] Loiseau P, Loiseau J, Jalon P, Zelicourt M. Is the risk of recurrence following a first epileptic event greater after single or multiple onset?.Epilepsia, 1999;40:87.

[23] Kho LK, Lawn ND, Dunne JW, Linto J. First seizure presentation: do multiple seizures within 24 hours predict recurrence? Neurology, 2006;67:1047-49.

[24] Daud AS, Ajloni S, EL-Salem K, Horani K, Otoom S, Daradkeh T. Risk of recurrence after a first unprovoked seizure: a prospective study among Jordanian children.Seizure, 2004;13:99-103.

[25] Panayotopoulos CP. The epilepsies: seizures, syndrome and management. Bladon Medical Publishing, Chipping Norton, UK. 2005. Web of Science/ Google Scholer

[26] Shinner S, Berg AT, Ptachewich Y et al. Sleep state and the risk of seizure recurrence following a first unprovoked seizure in childhood. Neurology 1993;43"701-6.

[27] Krauss G, Ampaw L, Krumholz A. Individual state driving restrictions for people with epilepsy in the US. Neurology 2001;57:1780-85.

[28] Beghi E, Sander JW. Epilepsy and driving. BMJ 2005;331:60-61.

[29] Scheffer IE, Bhatia KP, Lopes-Cendes I, Fish DR, Marsden CD, Andermann F, Andermann E, Desbiens R, Cendes F, Manson JI, Berkovic SF. Autosomal dominant frontal lobe epilepsy misdiagnosed as sleep disorder. Lancet 1994;343:515-7.

[30] Scheffer IE, Bhatia KP, Lopes-Cendes I, Fish DR, Marsden CD, Andermann F, Andermann E, Desbiens R, Cendes F, Manson JI et al. Autosomal dominant noctarnal frontal lobe epilepsy: a distinctive clinical disorder. Brain 1995;118:61-73.

[31] Annegers JF, Shirts SB, Hauser WA et al. Risk of recurrence after an initial unprovoked seizure. Epilepsia1986;27:43-50.

[32] Boulloche J, Leloup P, Mallet E et al. Risk of recurrence after a single, unprovoked, generalized tonic clonic seizure. Dev Med Child Neurol1989;31:626-32.

[33] Mussico M, Beghi E, Solari A, First Seizure Trial Group. Effect of antiepileptic treatment initiated after the first unprovoked seizure on the long term prognosis of epilepsy. Neurology.1994;44:337-8.

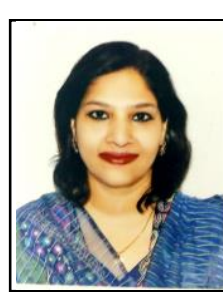

\section{Naznin Akter Ruby}

Place of birth: Barisal, Bangladesh.

Date of Birth: 27.11.1973.

She graduated from Khulna Medical College at the year 1998. Fellowship (FCPS) from Bangladesh College of Physicians and surgeons in Pediatrics in 2006, Fellowship (FCPS) from same institution in Pediatric Neurology at 2017.

Life members of ICNA (international child neurology association), AOCCN (Asian and Oceanian congress of child neurology). 